\title{
Perinatal and neonatal morbidity among infants of diabetic mothers at a university hospital in Central Saudi Arabia
}

\author{
Abdulrahman M. Al-Nemri, MD, Fahd Alsohime, MD, DES, Asfaq H. Shaik, MBBS, DCH, Ghasan A. El-Hissi, MBBS, \\ Mohammed I. Al-Agha, MBBS, MD, Nada F. Al-Abdulkarim, MBBS, MD, Sarar Mohamed, MD, FRCPCH.
}

\begin{abstract}
الأهداف : تحديد معدل المرض خلال الفترة المحيطة بالو لادة وأثناءها

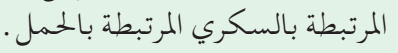

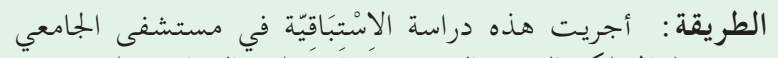

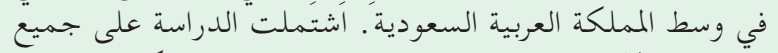

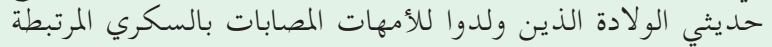

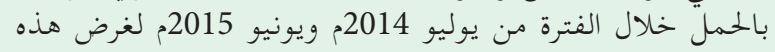

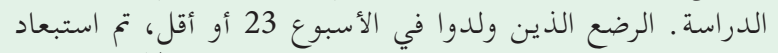

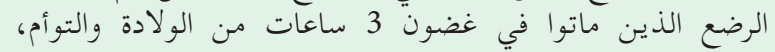
والسيدات الحوامل غير المسجلات في غاتل

النتائج : اشتملت الدراسة على 279 من السيدات و 289 رضع رضع.

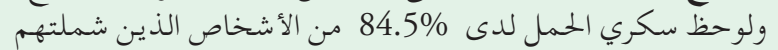
الدراسة نوع السكري الأول في

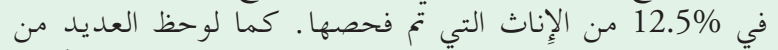

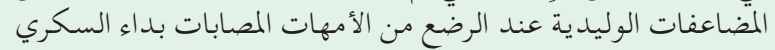

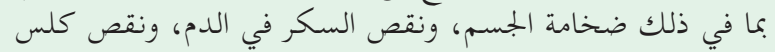

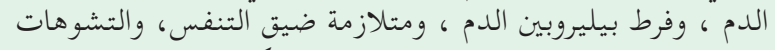

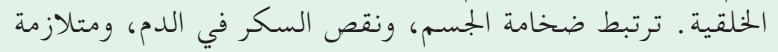

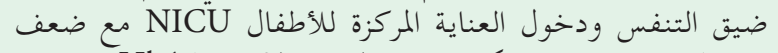

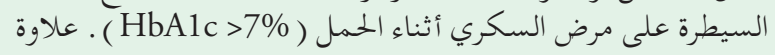

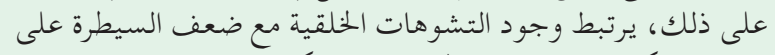

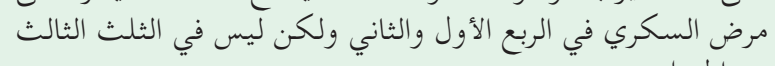
من الحمل . مرض المري

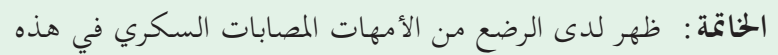

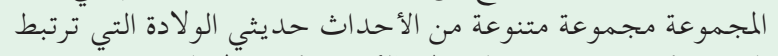

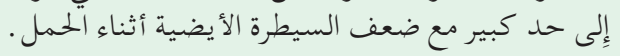

Objectives: To determine the perinatal and neonatal morbidity related to diabetes associated with pregnancy.

Methods: This is a prospective cohort study conducted at a tertiary university hospital in Central Saudi Arabia. All neonates born to mothers with pregnancy associated diabetes between July 2014 and June 2015 were recruited for the purpose of this study. Infants born at 23 weeks or less, infants who died within 3 hours of delivery, twins, and unbooked pregnant ladies were excluded from the study.

Results: A total of 279 ladies and 289 infants were enrolled in the study. Gestational diabetes was observed in $84.5 \%$ of study subjects, type 1 diabetes in $2.8 \%$, and type 2 diabetes in $12.5 \%$ of the females that were examined. A variety of neonatal complications were observed in infants of diabetic mothers including macrosomia, hypoglycemia, hypocalcemia, hyperbilirubinemia, respiratory distress syndrome, and congenital malformations. Macrosomia, hypoglycemia, respiratory distress syndrome, and NICU admission correlate with poor control of diabetes during pregnancy (HbAlc $>7 \%$ ). Moreover, the presence of congenital malformations correlates with poor diabetes control in the first and second trimester, but not in the third trimester.

Conclusion: Infants of diabetic mothers in this cohort developed a variety of neonatal events that largely correlates with poor metabolic control during pregnancy.

Saudi Med J 2018; Vol. 39 (6): 592-597 doi: 10.15537/smj.2018.6.22907

From the Department of Pediatric (Al-Nemri, Alsohime, Shaik, El-Hissi, Al-Agha, Al-Abdulkarim, Mohamed), from the Prince Abdullah bin Khaled Coeliac Disease Research Chair (Mohamed), Faculty of Medicine, King Saud University; and from the Department of Pediatric (Mohamed), Prince Sultan Military Medical City, Riyadh Saudi Arabia Riyadh, Kingdom of Saudi Arabia.

Received 11th March 2018. Accepted 16th April 2018.

Address correspondence and reprint request to: $D r$. Abdulrahman Al-Nemri, Pediatric Department, College of Medicine, King Saud University, Riyadh, Kingdom of Saudi Arabia. E-mail:aalnemri@ksu.edu.sa

ORCID ID: orcid.org/0000-0002-4081-3212 
I n terms of the global diabetes epidemic, Saudi Arabia has been rated among the top 10 countries with a high prevalence of diabetes. ${ }^{1}$ Recent studies have shown that the prevalence of type 2 diabetes mellitus (T2DM) is between $21-24 \%$ in Saudi Arabia. ${ }^{2-4}$ Moreover, the prevalence of diabetes in this country is expected to continue to rise as the result of increasing obesity, fast urbanization with changing dietary habits, and changes in life style. This rise is likely to be reflected in an increase in maternal and possibly gestational diabetes mellitus (GDM). It has been well documented that the prevalence of GDM has increased 5-fold in Saudi Arabia over the last 2 decades. ${ }^{4}$ Diabetes associated with pregnancy applies further strain on pregnant ladies leading to higher maternal, perinatal, and neonatal morbidities. ${ }^{5-8}$ Diabetes alters the physiological adaptation of both the mother and her fetus. This leads to adverse events during pregnancy including a higher risk of delivery by cesarean section (CS), shoulder dystocia, and other obstetric complications. ${ }^{9-12}$ The long term effects of GDM on mothers include the development of T2DM, obesity, and cardiovascular diseases. ${ }^{13-14}$ Likewise, GDM increases perinatal and neonatal complications including hypoglycemia, hypocalcemia, polythycemia, macrosomia, hyperbilirubinemia, respiratory distress syndrome, and congenital malformation. ${ }^{15-17}$ Most of these adverse events were attributed to poor metabolic control during pregnancy and inadequate maternal and neonatal care. Few retrospective studies in Saudi Arabia investigated the perinatal complications, however, these studies did not correlated these complications to the maternal hemoglobin A1C, prospectively. ${ }^{2,18,19}$ The objective of the study is to determine the perinatal and neonatal morbidity related to diabetes associated with pregnancy.

Methods. This is a prospective observation cohort study approved by the Institutional Review Board at the College of Medicine, King Khalid University Hospital, Riyadh, Kingdom of Saudi Arabia. Informed written consent was taken from all mothers participating in the study. We recruited all neonates born to diabetic mothers between July 2014 and June 2015 in King Khalid University Hospital (KKUH) situated within King Saud University Medical City, Riyadh, Saudi Arabia. All infants born to either Saudi or non-Saudi women with confirmed diabetes associated with

Disclosure. Authors have no conflict of interests, and the work was not supported or funded by any drug company. pregnancy were included in the study after obtaining their initial consent. Infants born at 23 weeks or less, infants who died within 3 hours of delivery, twins, and unbooked pregnant ladies were excluded from the study. All pregnant ladies attending our institute undergo a standard oral glucose tolerance test (OGTT) and the recording of glucose readings by venous sampling at 24 weeks of gestation. This entails giving a 75-g oral glucose load, and measuring the blood glucose levels at baseline fasting, then at one, 2, and 3 hours after the initial glucose intake. In our study, GDM was diagnosed if $\geq 2$ of the 4 blood glucose readings exceeded the cutoff levels which were as follows: fasting $(5.8 \mathrm{mmol} / \mathrm{l})$; one hour ( $10.8 \mathrm{mmol} / \mathrm{l}) ; 2$ hours $(8 \mathrm{mmol} / \mathrm{l})$; and 3 hours (6 mmol/l).

The pregnant ladies who participated in this study attended a regular antenatal clinic throughout their pregnancy. Their blood glucose, HbA1C levels were checked regularly. The infants were admitted to the nursery after delivery and the glucose level of all infants was checked on admission and 3 hourly, thereafter. The glucose level of infants was assessed using a hemogluco-check device. Hypoglycemia was defined as a glucose level $<2.6 \mathrm{mmol} / \mathrm{L}$, which was confirmed by obtaining a sample of venous blood and sending it to the laboratory for analysis. Samples of blood were analyzed for complete blood count (CBC), total bilirubin, magnesium, and calcium for all infants of diabetic mothers upon admission to the nursery. If the glucose level was $<2.6 \mathrm{mmol} / \mathrm{L}$, the infant was admitted to the neonatal intensive care unit (NICU) and dextrose IV was administered with continuous monitoring of glucose levels.

The age, mode of delivery, gravidity, and $\mathrm{HbA} 1 \mathrm{C}$ of the diabetic mothers were recorded. Any adverse neonatal outcome/complication including birth trauma, hypoglycemia, congenital anomalies, hypocalcaemia, hyperbilirubinemia, polycythemia, and hypomagnesemia were also reported.

Statistical analysis. Data was analyzed by using the IBM Statistical Package for Social Studies ${ }^{\circledR}$, version 22 (IBM Corp., New York, NY, USA) for Windows ${ }^{\circledast}$. Continuous variables were expressed as mean \pm standard deviation and categorical variables were expressed as percentages. An odds ratio with 95\% confidence interval was calculated. A Chi square test was used for categorical variables. A $p$-value $<0.05$ was considered statistically significant.

Results. Out of the 292 women who were recruited; 12 were excluded from the study. The reasons for exclusion included 10 twin pregnancies, 2 intrauterine fetal deaths (IUFD), and one neonate who died 2 
hours after delivery (who was born at 34 weeks) due to lung hypoplasia, multi-cystic dysplastic kidney, and oligohydramnios. Subsequently, a total of 279 mothers and 289 infants were enrolled in the study. The GDM was observed in $84.5 \%$ of the study subjects, type 1 diabetes in $2.8 \%$ of subjects, and type 2 diabetes in $12.5 \%$ of all diabetic mothers who participated in the study (Table 1). Poor diabetes control (HbA1c >7\%) was observed in a minority of patients in this cohort (Table 2).

The majority of diabetic mothers experienced spontaneous delivery. The exact figure was 177 (61.5\%); while 112 (38.5\%) mothers underwent an induced delivery. Compared to the subjects with either type 1 or type 2 diabetes, women with GDM had a statistically significant higher rate of elective cesarian sections $(p=0.026)$ (Table 3$)$.

A variety of neonatal complications were observed in infants of diabetic mothers during the course of this study (Table 4). A high level of HbA1c $(\mathrm{HbA1c}>7)$ in the first trimester was associated with adverse neonatal outcomes such as a long gestational period $(p=0.005)$ (odds ratio $[\mathrm{OR}]=5.35)$, hypoglycemia $(p=0.008)$ $(\mathrm{OR}=4.71)$, NICU admission $(p=0.02) \quad(\mathrm{OR}=3.32)$, and respiratory distress syndrome $(p=0.024)(\mathrm{OR}=3.55)$ (Table 5). Also, high levels of HbA1c (HbA1c >7) in the second trimester were positively associated with 1 an extended gestational age/period $(p=0.03)(\mathrm{OR}=4.59)$, hypoglycemia $(p=0.008) \quad(\mathrm{OR}=6.06), \quad$ congenital anomalies $(p=0.024)(\mathrm{OR}=5.00)$, and NICU admission $(p=0.029)(\mathrm{OR}=5.24)$ (Table 6). Likewise, high levels of HbA1c (where HbA1c >7) in the 3rd trimester were positively associated with large gestational age $(p=0.02)$ $(\mathrm{OR}=5.27)$, hypoglycemia $(p=0.03)(\mathrm{OR}=4.69)$, and hypocalcaemia $(p=0.013)(\mathrm{OR}=19.26)$ (Table 7$)$.

Discussion. Pregnant ladies with different types of diabetes are at high risk of developing obstetric complications and their offspring, too, are likely to develop perinatal and neonatal adverse events. ${ }^{5-8}$ In this prospective study, we investigated a cohort of pregnant ladies with diabetes from a country with a high prevalence of diabetes mellitus. Although the reported prevalence of type 2 diabetes in Saudi Arabia is $>21 \%$, we observed this type of diabetes in only $12 \%$ of our cohort. $^{2-4}$ This could be explained by the fact that type 2 diabetes is more common in older age groups compared to child bearing age groups.

Cesarean section delivery is more frequent in pregnant diabetic ladies in comparison with normal healthy pregnant mothers for many reasons. Such reasons include: macrocosmic fetuses, obstetric complications, and previous CS delivery. ${ }^{2}$ In our cohort, we observed that elective CS delivery was more frequent in pregnant ladies with type 2 diabetes compared to gestational and type 1 diabetes $(p=0.026)$. This is most

Table 1 - Characteristics of 279 mothers with diabetes mellitus (DM).

\begin{tabular}{lccccccc}
\hline DM type (number) & $\begin{array}{c}\text { Age } \\
\text { (mean years) }\end{array}$ & $\begin{array}{c}\text { Weight } \\
\text { (mean Kg) }\end{array}$ & Gravity & Gravity & $\begin{array}{c}\text { Parity } \\
(\text { mean })\end{array}$ & Miscarriage & BMI \\
\hline GDM, $\mathrm{n}=236$ & 32.68 & 69.1 & 4 & 4 & 2.4 & 1.03 & 35.5 \\
Type 1, $\mathrm{n}=8$ & 32.22 & 60.0 & 2.2 & 2.2 & 1.0 & 0.33 & 29 \\
Type 2, $\mathrm{n}=35$ & 36.41 & 80.5 & 5.08 & 5.08 & 3.75 & 0.82 & 36.8 \\
\hline \multicolumn{7}{c}{ BMI - body mass index } \\
\hline
\end{tabular}

Table 2 - Diabetic mothers with hemoglobin Alc levels >7\% ( $\mathrm{N}=279)$.

\begin{tabular}{lcccc}
\hline DM type & $\begin{array}{c}\text { 1st } \\
\text { trimester }\end{array}$ & $\begin{array}{c}\text { 2nd } \\
\text { trimester }\end{array}$ & $\begin{array}{c}\text { 3rd } \\
\text { trimester }\end{array}$ & $\begin{array}{c}\text { Overall \% of } \\
\text { mothers } \\
\text { with HbA1c }>7 \%\end{array}$ \\
\hline GDM & 1 & 3 & 3 & $(2.5)$ \\
T1DM & 1 & 0 & 1 & $(0.7)$ \\
T2DM & 14 & 8 & 7 & $(10.4)$ \\
Total & $16(5.73)$ & $11(3.94)$ & $11(3.94)$ & $(22.0)$ \\
\hline Values are expressed as number and percentage (\%). GDM - gestational \\
diabetes, HbA1c - hemoglobin A1c, DM - diabetes mellitus, \\
T1DM - type 1 DM, T2DM - type 2 DM \\
\hline \multicolumn{5}{c}{} \\
\hline
\end{tabular}

Table 3 - Mode of delivery of infants in 279 diabetic mothers.

\begin{tabular}{|c|c|c|c|c|c|}
\hline $\begin{array}{l}\text { Mode of } \\
\text { delivery }\end{array}$ & GDM & T1DM & T2DM & Total & $P$-value \\
\hline NSVD & $116(49.2)$ & $4(50)$ & $16(45.7)$ & $136(48.7)$ & 0.068 \\
\hline Elective CS & $37(15.7)$ & $2(25)$ & $12(34.3)$ & $51(18.3)$ & 0.026 \\
\hline Emergency CS & $63(26.7)$ & $2(25)$ & $6(17.1)$ & $71(25.5)$ & 0.480 \\
\hline Assisted & $20 \quad(8.4)$ & $(0)$ & $1 \quad(2.9)$ & $21 \quad(7.5)$ & 0.358 \\
\hline \multicolumn{6}{|c|}{$\begin{array}{c}\text { Values are expressed as number and percentage (\%). } \\
\text { NSVD - normal spontaneous vaginal delivery, CS - cesarean section, } \\
\text { GDM - gestational diabetes, T1DM - type } 1 \text { diabetes mellitus, } \\
\text { T2DM - type } 2 \text { diabetes mellitus }\end{array}$} \\
\hline
\end{tabular}


Table 4 - Association of neonatal complication with type of diabetes in pregnant mothers.

\begin{tabular}{|c|c|c|c|c|c|}
\hline $\begin{array}{l}\text { Neonatal outcome/complication suffered } \\
\text { (normal range) }\end{array}$ & $\begin{array}{c}\text { GDM } \\
(\mathrm{n}=244)\end{array}$ & $\begin{array}{c}\text { T1DM } \\
(n=9)\end{array}$ & $\begin{array}{l}\text { T2DM } \\
(\mathbf{n}=36)\end{array}$ & Total & $P$-value \\
\hline Large gestational age $(>4 \mathrm{~kg})$ & $25(10.2)$ & 0 & $6(16.0)$ & $31(10.7)$ & 0.291 \\
\hline Birth trauma & $13(5.3)$ & 0 & $1(2.8)$ & $14(4.8)$ & 0.633 \\
\hline IUGR (Wt \& Ht < 10th centile for GA) & $34(13.9)$ & 0 & $3(8.3)$ & $37(12.8)$ & 0.325 \\
\hline Hypoglycemia (2.8-4.4 mmole/dl) & $26(10.7)$ & $3(33.3)$ & $5(13.9)$ & $34(11.8)$ & 0.107 \\
\hline Hypocalcaemia (0.7-1.14 mmole/dl) & $1 \quad(0.4)$ & $1 \quad(2.9)$ & $3(1.3)$ & $5(1.8)$ & 0.085 \\
\hline Hyperbillirubenemia (according to NICU CPG) & $28(11.5)$ & $4(44.4)$ & $5(13.9)$ & $37(12.8)$ & 0.014 \\
\hline Hypomagnesemia (0.7-1.1 mmole/dl) & $47(19.3)$ & $3(33.3)$ & $4(11.1)$ & $54(18.7)$ & 0.261 \\
\hline Polycythemia (36-65\%) & $12(5.0)$ & 0 & $4(11.4)$ & $16(5.6)$ & 0.229 \\
\hline Prematurity & $35(14.3)$ & $2(22.2)$ & $7(19.4)$ & $44(15.2)$ & 0.611 \\
\hline Congenital anomalies & $22(9.0)$ & $1(11.1)$ & $6(16.7)$ & $29(10.0)$ & 0.36 \\
\hline NICU admission & $51(20.9)$ & $6(66.7)$ & $8(22.2)$ & $65(22.5)$ & 0.005 \\
\hline Respiratory distress syndrome & $33(13.5)$ & $4(44.4)$ & $5(13.9)$ & $42(14.5)$ & 0.035 \\
\hline Hypoxic ischemic encephalopathy & $1 \quad(0.4)$ & 0 & $1(2.8)$ & $2(0.7)$ & 0.269 \\
\hline
\end{tabular}

Table 5 - Adverse neonatal outcome in relation to high HbA1C level in the first trimester.

\begin{tabular}{|c|c|c|c|c|c|c|c|}
\hline \multirow{3}{*}{$\begin{array}{l}\text { Neonatal complications } \\
\text { Large gestational age }\end{array}$} & \multirow{2}{*}{$\begin{array}{c}\mathrm{HbA1c}<7 \\
\mathrm{n}=270\end{array}$} & \multirow{2}{*}{$\begin{array}{c}\mathrm{HbA1c}>7 \\
\mathrm{n}=17\end{array}$} & \multirow[t]{2}{*}{ Total } & \multirow{2}{*}{$\begin{array}{l}\text { Odds } \\
\text { ratio }\end{array}$} & \multicolumn{2}{|c|}{$95 \% \mathrm{CI}$} & \multirow[t]{2}{*}{$P$-value } \\
\hline & & & & & Low & High & \\
\hline & $25 \quad(9.3)$ & $6(35.3)$ & 31 & 5.35 & 1.82 & 15.69 & 0.005 \\
\hline Birth trauma & $14 \quad(5.2)$ & 0 & 14 & - & & & 0.417 \\
\hline Intrauterine growth restriction & $36(13.3)$ & $1(5.9)$ & 37 & 0.41 & 0.05 & 3.16 & 0.328 \\
\hline Hypoglycemia & $28(10.4)$ & $6(35.3)$ & 34 & 4.71 & 1.62 & 13.73 & 0.008 \\
\hline Hypocalcemia & $5(1.8)$ & 0 & 5 & - & & & 0.735 \\
\hline Hypomagnesemia & $50(18.5)$ & $4(23.5)$ & 54 & 1.40 & 0.43 & 4.52 & 0.401 \\
\hline Hyperbilirubinemia & $33(12.2)$ & $4(23.5)$ & 37 & 2.21 & 0.68 & 7.18 & 0.162 \\
\hline Polycythemia & $15(5.5)$ & $1 \quad(5.9)$ & 16 & 1.12 & 0.14 & 9.06 & 0.634 \\
\hline Prematurity & $39(14.4)$ & $5(29.4)$ & 44 & 2.47 & 0.82 & 7.39 & 0.1 \\
\hline Congenital anomalies & $25 \quad(9.3)$ & $4(23.5)$ & 29 & 3.02 & 0.91 & 9.95 & 0.079 \\
\hline NICU admission & $57(21.1)$ & $8(47.1)$ & 65 & 3.32 & 1.23 & 9.00 & 0.02 \\
\hline Respiratory distress syndrome & $36(13.3)$ & $6(35.3)$ & 42 & 3.55 & 1.23 & 10.18 & 0.024 \\
\hline Hypoxic ischemic encephalopathy & $1 \quad(0.4)$ & $1 \quad(5.9)$ & 2 & - & & & 0.115 \\
\hline
\end{tabular}

probably because ladies with type 2 diabetes, in this study, were either older or had a higher gravity, parity, and BMI than their counterparts with type 1 diabetes and GDM..$^{2-6}$ All these are risk factors for obstetric and perinatal complications and, therefore, doctors are likely to plan elective CS for such individuals. However, various studies have reported a high rate of cesarean delivery in GDM patients despite proper management of glucose levels during pregnancy. ${ }^{1-3,5}$ The outcomes of pregnancies complicated with GDM were significantly worse than those of non-diabetic women with such patients being 1.7 times more likely to deliver by CS. ${ }^{3}$ Our data showed that certain perinatal adverse effects such as macrosomia, hypoglycemia, respiratory distress syndrome, and NICU admission all correlate with poor control of diabetes during pregnancy (where HbA1c levels $>7 \%$ ). This was expected; however, as the poor control of diabetes during pregnancy subjects the fetus to high glucose levels and, therefore, stimulates a higher secretion of insulin by the fetal pancreatic B cells. ${ }^{6,7}$ Insulin is an anabolic hormone that promotes intrauterine fetal growth leading to macrosomia, which 
Table 6 - Association between adverse neonatal outcomes/complications in relation to high hemoglobin (HbA1c) levels in the second trimester.

\begin{tabular}{|c|c|c|c|c|c|c|c|}
\hline \multirow[t]{2}{*}{ Neonatal complications } & \multirow{2}{*}{$\begin{array}{c}\mathrm{HbA1c}<7 \\
\mathrm{n}=275\end{array}$} & \multirow{2}{*}{$\begin{array}{c}\mathrm{HbA1c}>7 \\
\mathrm{n}=12\end{array}$} & \multirow[t]{2}{*}{ Total } & \multirow{2}{*}{$\begin{array}{l}\text { Odds } \\
\text { ratio }\end{array}$} & \multicolumn{2}{|c|}{$95 \% \mathrm{CI}$} & \multirow[t]{2}{*}{$P$-value } \\
\hline & & & & & Low & High & \\
\hline Large gestational age & $27(9.8)$ & $4(33.3)$ & 31 & 4.59 & 1.30 & 16.26 & 0.03 \\
\hline Birth trauma & $12(4.3)$ & $2(16.7)$ & 14 & 4.38 & 0.86 & 22.25 & 0.11 \\
\hline Intra-uterine growth restriction & $36(13.1)$ & $1 \quad(8.3)$ & 37 & 0.60 & 0.08 & 4.82 & 0.328 \\
\hline Hypoglycemia & $29(10.5)$ & $5(41.7)$ & 34 & 6.06 & 1.81 & 20.33 & 0.008 \\
\hline Hypocalcaemia & $5(1.8)$ & $0 \quad(0)$ & 5 & - & & & 0.809 \\
\hline Hypomagnesemia & $53(19.3)$ & $1 \quad(8.3)$ & 54 & 0.36 & 0.05 & 2.87 & 0.304 \\
\hline Hyperbilirubinemia & $36(13.1)$ & $1(8.3)$ & 37 & 0.60 & 0.08 & 4.82 & 0.162 \\
\hline Polycythemia & $15(5.45)$ & $1 \quad(8.3)$ & 16 & 1.55 & 0.19 & 12.83 & 0.505 \\
\hline Prematurity & $43(15.6)$ & 1 (8.3) & 44 & 0.49 & 0.06 & 3.90 & 0.426 \\
\hline Congenital anomalies & $25(9.1)$ & $4(33.3)$ & 29 & 5.00 & 1.41 & 17.78 & 0.024 \\
\hline NICU admission & $58(21.1)$ & $7(58.3)$ & 65 & 5.24 & 1.60 & 17.11 & 0.029 \\
\hline Hypoxic ischemic encephalopathy & $1 \quad(0.4)$ & $1(8.3)$ & 2 & - & & & 0.082 \\
\hline
\end{tabular}

Values are expressed as number and percentage (\%). NICU - neonatal intensive care unit, $95 \%$ CI - 95\% confidence intervals

Table 7 - Association between adverse neonatal outcomes/complications in relation to high hemoglobin (HbA1c) levels in the third trimester.

\begin{tabular}{|c|c|c|c|c|c|c|c|}
\hline \multirow[t]{2}{*}{ Neonatal complications } & \multirow{2}{*}{$\begin{array}{c}\mathrm{HbA1c}<7 \\
\mathrm{n}=276\end{array}$} & \multirow{2}{*}{$\begin{array}{c}\mathrm{HbA} 1 \mathrm{c}>7 \\
\mathrm{n}=11\end{array}$} & \multirow[t]{2}{*}{ Total } & \multirow{2}{*}{$\begin{array}{l}\text { Odds } \\
\text { ratio }\end{array}$} & \multicolumn{2}{|c|}{$95 \% \mathrm{CI}$} & \multirow[t]{2}{*}{$P$-value } \\
\hline & & & & & Low & High & \\
\hline Large gestational age & $27 \quad(9.8)$ & $4(36.4)$ & 31 & 5.27 & 1.45 & 19.16 & 0.02 \\
\hline Birth trauma & $14 \quad(5.1)$ & 0.00 & 14 & - & & & 0.57 \\
\hline Intra-uterine growth restriction & $37(13.4)$ & 0.00 & 37 & - & & & 0.21 \\
\hline Hypoglycemia & $30(10.9)$ & $4(36.4)$ & 34 & 4.69 & 1.30 & 16.95 & 0.03 \\
\hline Hypocalcemia & $3(1.1)$ & $2(18.2)$ & 5 & 19.26 & 2.86 & 129.88 & 0.01 \\
\hline Hypomagnesemia & $53(19.2)$ & $1 \quad(9.1)$ & 54 & 0.40 & 0.05 & 3.19 & 0.35 \\
\hline Hyperbilirubinemia & $34(12.3)$ & $3(27.3)$ & 37 & 2.67 & 0.68 & 10.55 & 0.16 \\
\hline Polycythemia & $16(5.8)$ & 0.00 & 16 & - & & & 0.53 \\
\hline Prematurity & $41(14.9)$ & $3(27.3)$ & 44 & 2.15 & 0.55 & 8.44 & 0.23 \\
\hline Congenital Anomalies & $27 \quad(9.8)$ & $2(18.2)$ & 29 & 2.05 & 0.42 & 9.98 & 0.31 \\
\hline NICU admission & $61(22.1)$ & $4(36.4)$ & 65 & 2.01 & 0.57 & 7.11 & 0.22 \\
\hline Respiratory distress syndrome & $39(14.1)$ & $3(27.3)$ & 42 & 2.28 & 0.58 & 8.96 & 0.21 \\
\hline Hypoxic ischemic encephalopathy & $1 \quad(0.4)$ & $1 \quad(9.1)$ & 2 & - & & & 0.08 \\
\hline
\end{tabular}

Values are expressed as number and percentage (\%). NICU - neonatal intensive care unit,

95\% CI - 95\% confidence intervals

in turn results in other neonatal adverse effects. This fact is in agreement with previous studies which have reported that poor diabetes control during pregnancy is positively associated with increased maternal and perinatal morbidity and mortality. ${ }^{2-6}$ We observed that the tendency towards the presence of congenital malformations correlates with poor diabetes control in the first and second trimester but not in the third trimester. This is because organogenesis occurs in early pregnancy and therefore the risk of congenital malformation is higher when the infant is exposed to poor metabolic control during this period. Congenital malformation amongst infants of diabetic mothers was the major reason for increased morbidity and mortality rates of these infants. ${ }^{12-14}$

The study assumes significance due to the fact that a substantial number of study subjects developed a variety of neonatal adverse effects including: macrosomia, hyperbilirubinemia, RDS, admission in NICU, hypoglycemia, and congenital anomalies irrespective of the type of diabetes they had. However, because the study was performed at a single center 
and included a low population cohort size, the results that were obtained from the data that was accrued has limited generalizability. Moreover, the nutritional status of the study subjects throughout their period of pregnancy and the non-inclusion of controls could have influenced the study results. Therefore, we recommend that larger case control studies be conducted across multiple centers throughout the Kingdom of Saudi Arabia in order to draw firm conclusions regarding the relationship between perinatal complication $\mathrm{HbA1c}$ levels in diabetic pregnant mothers.

In conclusion, then, we have shown that infants of diabetic mothers suffer complications which correlate with poor blood sugar level control during pregnancy as indicated by high maternal $\mathrm{HbA1c}$ levels.

Acknowledgment. This research has been financially supported by Prince Abdullah Ben Khalid Celiac Disease Research Chair, under the Vice Deanship of Research Chairs, King Saud University, Riyadh, Kingdom of Saudi Arabia. The authors would like to thank all the participants involved in this study.

\section{References}

1. Bener A, Al-Nufal M, Vachhani PJ, Ali AI, Samson N, Saleh NM. Maternal complications and neonatal outcome in Arab women of a fast developing country. J Family Community Med 2013; 20: 27-34.

2. Gasim T. Gestational diabetes mellitus: maternal and perinatal outcomes in 220 Saudi women. Oman Med J 2012; 27: 140-144.

3. Wahabi HA. Diabetes mellitus in pregnancy: a clinical and public health problem [Doctoral dissertation]. University of Warwick; 2014.

4. Al-Daghri NM, Al-Attas OS, Alokail MS, Alkharfy KM, Yousef M, Sabico SL, et al. Diabetes mellitus type 2 and other chronic non-communicable diseases in the central region, Saudi Arabia (Riyadh cohort 2): a decade of an epidemic. BMC medicine 2011; 9: 76.

5. Al-Hakeem MM. Pregnancy outcome of gestational diabetic mothers: experience in a tertiary center. J Family Community Med 2006; 13: 55-59.

6. Metzger BE. Long-term outcomes in mothers diagnosed with gestational diabetes mellitus and their offspring. Clin Obstet Gynecol 2007; 50: 972-979.
7. Amarzouki A. Maternal and neonatal outcome of controlled gestational diabetes mellitus versus high risk group without gestational diabetes mellitus: a comparative study. Med Glas (Zenica) 2013; 10: 70-74.

8. Persson M, Norman M, Hanson U. Obstetric and perinatal outcomes in type 1 diabetic pregnancies. Diabetes care 2009; 32: 2005-2009.

9. Lasheen AE, Abdelbasit OB, Seidahmed MZ, Hussein KA, Miqdad AM, Al Zahrani MH, et al. Infants of diabetic mothers. A cohort study. Saudi Med J 2014; 35: 572-577.

10. Al-Qahtani MH. Infants of diabetic mothers: 4 years analysis of neonatal care unit in a teaching hospital, Saudi Arabia. Saudi J Med Med Sci 2014; 2: 151-156.

11. Köck K, Köck F, Klein K, Bancher-Todesca D, Helmer H. Diabetes mellitus and the risk of preterm birth with regard to the risk of spontaneous preterm birth. J Matern Fetal Neonatal Med 2010; 23: 1004-1008.

12. Nold JL, Georgieff MK. Infants of diabetic mothers. Pediatric Clinics of North America 2004; 51: 619-637.

13. Langer O, Miodovnik M, Reece EA, Rosenn BM. The proceedings of the diabetes in pregnancy study group of North America 2009 conference. J Matern Fetal Neonatal Med 2010; 23: 196-198.

14. Johns K, Olynik C, Mase R, Kreisman S, Tildesley H. Gestational diabetes mellitus outcome in 394 patients. J Obstet Gynaecol Can 2006; 28: 122-127.

15. Peticca P, Keely EJ, Walker MC, Yang Q, Bottomley J. Pregnancy outcomes in diabetes subtypes: how do they compare? A province-based study of Ontario, 2005-2006. J Obstet Gynaecol Can 2009; 31: 487-496.

16. Opara PI, Jaja T, Onubogu UC. Morbidity and mortality amongst infants of diabetic mothers admitted into a special care baby unit in Port Harcourt, Nigeria. Ital J Pediatr 2010; 36: 77.

17. Bricelj K, Tul N, Lucovnik M, Kronhauser-Cerar L, Steblovnik L, Verdenik I, et al. Neonatal respiratory morbidity in latepreterm births in pregnancies with and without gestational diabetes mellitus. J Matern Fetal Neonatal Med 2016; 30: 377-379.

18. Al-Dabbous IA, Owa JA, Nasserallah ZA, Al-Qurash IS. Perinatal moribidity and mortality in offspring of diabetic mothers in Qatif, Saudi Arabia. Eur J Obstet Gynecol Reprod Biol 1966; 65: 165-169.

19. Al-Khalifah R, Al-Subaihin A, Al-Kharfi T, Al-Alaiyan S, AlFaleh KM. Neonatal short-term outcomes of gestational diabetes mellitus in saudi mothers: a retrospective cohort study. J Clin Neonatol 2012; 1: 29-33. 